\title{
Phenylephrine induced fixed drug eruption: a rare case of cross sensitivity
}

\author{
Mahesh Chander Gupta ${ }^{1}$, Mamta Rani ${ }^{1}$, Kamal Aggarwal $^{2}$
}

\begin{abstract}
${ }^{1}$ Department of Pharmacology, Pandit Bhagwat Dayal Sharma Post Graduate Institute of Medical Sciences, Rohtak, Haryana, India,

${ }^{2}$ Department of Skin and V.D., Pandit Bhagwat Dayal Sharma

Post Graduate Institute of Medical Sciences, Rohtak, Haryana, India
\end{abstract}

Received: 10 June 2016

Accepted: 04 July 2016

*Correspondence to:

Dr. Mamta Rani,

Email: drkuldeep83@gmail.com

Copyright: (C) the author(s), publisher and licensee Medip Academy. This is an openaccess article distributed under the terms of the Creative Commons Attribution NonCommercial License, which permits unrestricted noncommercial use, distribution, and reproduction in any medium, provided the original work is properly cited.

\begin{abstract}
Fixed drug eruption (FDE) is a type of dermatosis characterized by recurrent lesions at exactly the same sites with each administration of the causative agents. FDEs are common types of drug eruptions amongst all cutaneous druginduced side effects, mostly by intermittent exposure. Multiple drugs with common chemical structure can cause same type of lesions at same site called as cross sensitivity. There are many causative agents and the incidence of FDEs for a particular drug depends on the frequency of its use. Though usually not severe or fatal, cosmetic embarrassment is main problem, especially when they recur on the previously affected sites leaving behind residual hyperpigmentation. Phenylephrine is a sympathomimetic agent, given orally for the symptomatic relief of nasal congestion. It is also commonly combined with other ingredients in preparations intended for the relief of cough and cold symptoms. Considering the frequent use of Phenylephrine, associated drug eruptions generally appear to be rare, cross sensitivity with pseudoephedrine is even rarer. In our case phenylepherine was self-administered to control cold induced congestion and patient developed FDE on vermillion of upper lip, which healed after 2 weeks leaving hyperpigmentation and reappear on same site after re-challenge also. She has history of FDEs due to pseudoephedrine on same site on lips. This is a rare case of sympathomimetics induced FDE with cross sensitivity between phenylepherine and pseudoephedrine; hence we are reporting it here.
\end{abstract}

Keywords: FDE, Cross sensitivity, Phenylepherine, Pseudoephedrine sympathomimetics

\section{INTRODUCTION}

Fixed drug eruption (FDE) is a type of dermatosis characterized by recurrent lesions at exactly the same sites with each administration of the causative agents. Brocq coined the term 'fixed eruption' in 1984 to describe a pattern of skin eruptions due to antipyrine. T-cell mediated FDE, is a localized variant of a delayed type hypersensitivity reaction in response to drugs and is characterized by sudden onset of single or multiple sharply demarcated, erythematous macules and plaques. ${ }^{1}$ FDEs are common types of drug eruptions amongst all cutaneous drug-induced side effects, mostly by intermittent exposure. Multiple drugs with common chemical structure can cause same type of lesions at same site. Itching or burning is usually associated with FDEs, well circumscribed, erythematous macules, patches, or plaques that leave hyperpigmentation after resolving. Occasionally vesicles or bullae may be seen. There are many causative agents and the incidence of FDE for a particular drug depends on the frequency of its use. Analgesics, antibiotics, muscle relaxants and anticonvulsants are common FDEs causing drugs. Besides drugs fruits, nuts, nutritional supplements, 
artificial colouring agents are other uncommonly suspected culprits.

According to clinical features and type of lesions, different types of fixed drug eruption have been described..$^{2-7}$ These include pigmenting fixed drug eruption, generalized or multiple, Linear, wandering, non-pigmenting FDEs, bullous, eczematous, urticarial, erythema dyschromicum perstans like FDE, vulvitis, oral and psoriasiform. One more type recently observed is cellulitis like eruption. ${ }^{8}$

To identify the causative agent, re-challenge to the suspected offending drug is the only known test. Patch testing and oral provocation have been used to identify the suspected agent and check for cross-sensitivities to medications. ${ }^{9,10}$ Skin biopsy is the procedure of choice for confirming diagnosis.

Only symptomatic treatment is there for fixed drug eruptions (FDEs), including systemic antihistamines and topical corticosteroids. If infection is there, antibiotics and proper wound care may be needed. Hyperpigmentation due to inflammation may take several months to resolve.

Phenylephrine is a sympathomimetic agent, given orally for the symptomatic relief of nasal congestion. They are also commonly combined with other ingredients in preparations intended for the relief of cough and cold symptoms. Considering the frequent use of phenylephrine, associated drug eruptions generally appear to be rare, cross sensitivity with pseudoephedrine is even rarer and any case report of this type is not documented in literature.

Certain assessment scales are helpful to establish the causality. The commonly used scales are Naranjo's assessment scale and WHO-UMC scale for standardized case causality assessment.

Re-challenge also called oral provocation test helps to establish the diagnosis as in our patient. Other methods include patch testing, prick test and intradermal skin test which have a positivity of $43 \%, 23 \%$ and $67 \%$ respectively. ${ }^{11}$

No case of this type has been reported previously. Here the first case report describes appearance of FDE over vermilion of lips in a 30 year old woman who had intermittent exposure to phenylepherine, also history of same FDE on lips with pseudoephedrine, a case of cross sensitivity. No specific treatment was instituted in this case and lesions healed over the time period of 2 weeks with encrustation.

\section{CASE REPORT}

A 30 year old female patient presented with blisters measuring about $1 \mathrm{~cm}$ over vermilion of upper lip along with burning and itching. History revealed that she has taken an OTC fixed dose combination drug MEDLER (paracetamol $325 \mathrm{mg}$, phenylepherine $10 \mathrm{mg}$, chlorpheniramine $2 \mathrm{mg}$ and caffeine anhydrous $30 \mathrm{mg}$ ) 2 times a day. On $2^{\text {nd }}$ day painful erythematous macule of 3-4 mm along with swelling of upper lip developed. On $3^{\text {rd }}$ day blister of about $1 \mathrm{~cm}$ filled with serous fluid developed on same site associated with burning and itching [Figure 1 (a)].
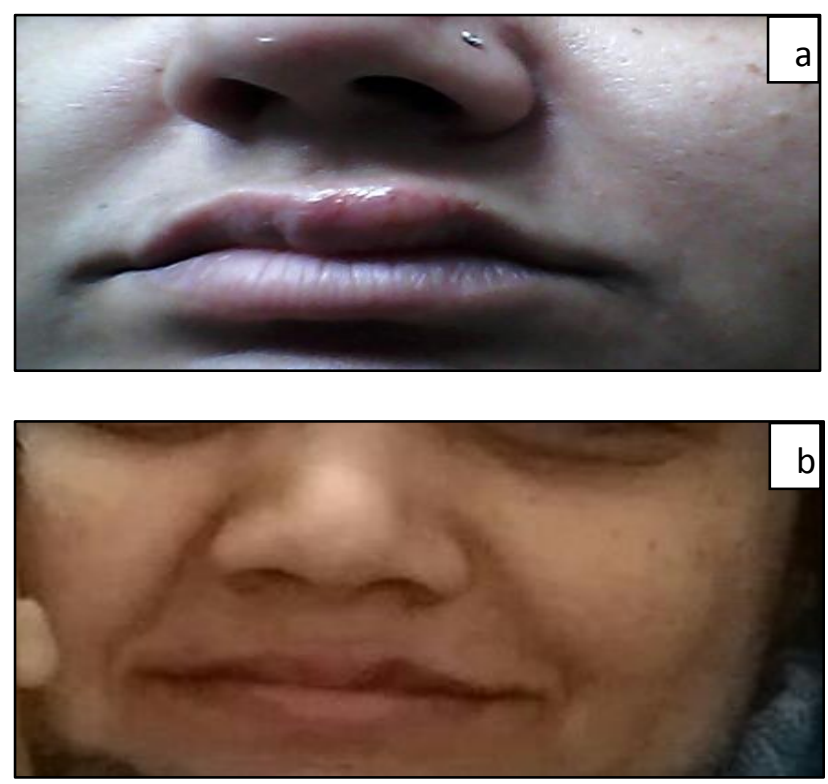

Figure 1 (a and b): Initial presentation with bullous eruptions and healed lesion with hyperpigmentation on vermilion of upper lip.

Patient was afebrile and there were no other associated systemic complaints. Her biochemical and haematological parameters were within normal limits. On examination she was alert, her pulse and B.P. were normal. She had no pallor, no icterus, no lymphadenopathy, no clubbing and no pedal oedema.

She had history of blistering type FDEs below the eyes, on cheeks, arms and abdomen from ibuprofen and mefenamic acid. History also revealed that she had FDEs on vermilion of lips several times after taking OTC SINAREST (paracetamol $500 \mathrm{mg}$, pseudoephedrine hydrochloride $10 \mathrm{mg}$, chlorpheniramine maleate $2 \mathrm{mg}$ and caffeine anhydrous $30 \mathrm{mg}$ ). After consulting a doctor she stopped taking SINAREST and started selfmedication with MEDLER whenever she had cold with same problem happening again 2 times. $3^{\text {rd }}$ times she reported to the clinician with the same problem.

Based on patient history and clinical examination a provisional diagnosis of FDEs due to fixed drug combination was made. As patient had FDEs due to FDC containing pseudoephedrine $10 \mathrm{mg}$. Phenylepherine was considered as suspected culprit, as a case of cross sensitivity with psedoephedrine. No skin biopsy was done. As patient had taken the FDC with antihistaminic 
chlorpheniramine $2 \mathrm{mg}$, so patch test was not done, as test could give false results.

Drug was stopped and no specific treatment was given. She was asked to review in OPD after 2 weeks. The lesions healed with encrustation leaving hyperpigmented area of 3-4 $\mathrm{mm}$ on same site after removal of crust [Figure 1(b)].

She was again reviewed in OPD after 10 days and oral provocation test was applied with same FDC (Medler) after taking patient's consent, as previous reaction was local and without any systemic finding. This was a rechallenge which turned out to be positive (Figure 2). Then causality assessment was done using WHO-UMC scale as certain and case was reported to regional pharmacovigilance centre. $^{12}$

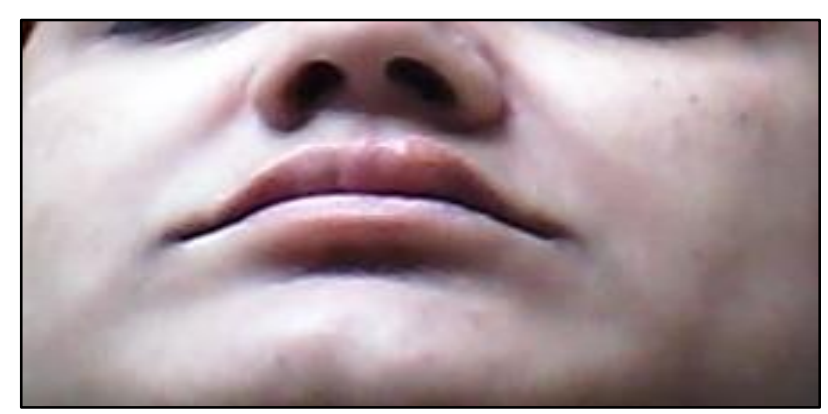

Figure 2: Recurrent lesion over vermilion of upper lip after 2 weeks on application of oral provocation test with same FDC.

She has history of taking paracetamol $500 \mathrm{mg}$ alone several times in past as analgesic and antipyretic without any eruption or reaction. So, paracetamol was excluded as culprit drug. Chlorpheniramine is antihistaminic, phenylepherine was considered as suspected drug.

She was advised against self-medication and not to take phenylepherine or pseudoephedrine either alone or as FDCs. After 9 weeks she had fever and rhinitis again. Subsequently she took paracetamol $500 \mathrm{mg}$ and chlorpheniramine $4 \mathrm{mg}$ as separate drugs. No hypersensitivity reaction occurred, excluding paracetamol and chloropheniramine as suspected drug, confirming the diagnosis.

Thus patient was diagnosed as case of phenylepherine induced fixed drug eruption having cross sensitivity with pseudoephedrine on the basis of oral provocation tests and history.

\section{DISCUSSION}

FDE is a cutaneous ADR which is characterized by recurrent eruptions when the offending drug is readministered. The hallmark of FDEs is the recurrence in the same site on repeated administration of the offending drug. ${ }^{13}$ Though usually not severe or fatal, cosmetic embarrassment is main problem, especially when they recur on the previously affected sites leaving behind residual hyperpigmentation. In our case repeated lesion occur on same site after re-challenge with the offending FDC and individual offending drug was diagnosed after exclusion on the basis of history and oral challenge test.

This might be case of cross sensitivity between phenylepherine and other sympathomimetic drugs like pseudoephedrine. Both are included in the phenylamine family, having 2 main groups of drugs: phenylpropanolamine- derived (ephedrine, pseudoephedrine, and norephedrine) and phenylethanolamine-derived (phenylephrine and epinephrine). Potential cross reaction among them could be explained by very close chemical structures of these drugs. But the results reported in the literature are controversial, as no case report of cross sensitivity between phenylepherine and pseudoephedrine is mentioned. Although sympathomimetic drugs are used often, allergic reactions are rare, especially when the drugs are administered systemically. Cross-sensitivity may exist among catecholamine derivatives, although reported data on this are contradictory. ${ }^{14}$

The literature contains many reports of contact dermatitis to phenylephrine and FDEs due to pseudoephedrine. ${ }^{15,16}$ One report of fixed drug eruption due to phenylepherine is also documented. ${ }^{17}$ One report of cross sensitivity between phenylepherine and ethylepherine is also reported. ${ }^{18}$ To best of our knowledge no such case of this type is reported in literature.

On WHO-UMC scale ADR is casually assessed as certain. A patch test might have been useful in this case, but it must be done on cases that are not on any immunosuppressants or anti-allergic agents in the past 48 hours. In our case, patient was on tablet Medler (FDC containing antihistaminic chlorpheniramine $2 \mathrm{mg}$ ) from past 72 hours. Hence, a patch test would have yielded false results.

\section{CONCLUSION}

Phenylepherine and other sympathomimetics are commonly used as nasal decongestants as single agent or in FDCs available as OTC products. In our case fixed drug eruption will be related to phenylepherine due to suggestive relationship between drug intake and reaction onset, the relapse of eruption after withdrawal and reoccurrence on same site after re-challenge. Also history revealed cross sensitivity with pseudoephedrine. Thus, this report emphasizes a rare case of uncommon localization of FDE due to phenylepherine as well as cross sensitivity with pseudoephedrine. Clinicians should keep in mind and should be aware of the possibility of reactions to these drugs also, which are very frequently prescribed and available also as OTC drug products to manage symptoms of rhinitis. 
Funding: No funding sources

Conflict of interest: None declared

Ethical approval: Not required

\section{REFERENCES}

1. Sehgal VN, Srivastava G. Fixed drug eruption (FDE): changing scenario of incriminating drugs. Int $\mathrm{J}$ Dermatol. 2006;45:897-908.

2. Mahboob A, Haroon TS. Drugs causing fixed eruptions: a study of 450 cases. Int J Dermatol. 1998;37(11):833-8.

3. Ozkaya-Bayazit E. Specific site involvement in fixed drug eruption. J Am Acad Dermatol. 2003;49(6):1003-7.

4. Ozkaya-Bayazit E, Bayazit H, Ozarmagan G. Drug related clinical pattern in fixed drug eruption. Eur $\mathrm{J}$ Dermatol. 2000;10(4):288-91.

5. Fischer G. Vulvar fixed drug eruption. A report of 13 cases. J Reprod Med. 2007;52(2):81-6.

6. Gupta S, Gupta S, Mittal A, David S. Oral fixed drug eruption caused by gabapentin. J Eur Acad Dermatol Venereol. 2009;23(10):1207-8.

7. Katoulis AC, Bozi E, Kanelleas A, Makris A, Alevizou A, Panagiotides I, et al. Psoriasiform fixed drug eruption caused by nimesulide. Clin Exp Dermatol. 2009;34(7):e360-1.

8. Fathallah N, Ben Salem C, Slim R, Boussofara L, Ghariani N, Bouraoui K. Acetaminophen-induced cellulitis-like fixed drug eruption. Indian J Dermatol. 2011;56(2):206-8.

9. Lammintausta K, Kortekangas-Savolainen O. Oral challenge in patients with suspected cutaneous adverse drug reactions: findings in 784 patients during a 25-year-period. Acta Derm Venereol. 2005;85(6):491-6.

10. Lammintausta K, Kortekangas-Savolainen O. The usefulness of skin tests to prove drug hypersensitivity. Br J Dermatol. 2005;152(5):968-74.
11. Barbaud A, Reichert-Penetrat S, Trechot P, JacquinPetit MA, Ehlinger A, Noirez V, et al. The use of skin testing in investigation of adverse cutaneous drug reactions. Br J Dermatol. 1998;149:139.

12. The use of the WHO-UMC system for standardized case causality assessment. Available at http://www.who-umc.org/graphics/24734.pdf. Accessed on 2 December 2014.

13. Balakrishna S, Vijayakumar S, Kumar PS, Upadhyaya J. Stevens-Johnson syndrome (SJS) and fixed drug eruption (FDE): A case report. Int J Pharm Sci Lett. 2013;3:257-9.

14. Barranco R, Rodriquez A, de Barrio M, Trujillo MJ, de Frutos C, Matheu V, et al. Sympathomimetic drug allergy: cross reactivity study by patch test. Am J Clin Dermatol. 2004;5(5):351-5.

15. Akita $\mathrm{H}$, Akamatsu H, Matsugana K. Allergic contact dermatitis due to phenylephrine hydrochloride, with an unusual patch test reaction. Contact Dermatitis. 2003;49(5):232-5.

16. Vidal C, Prieto A, Perez Carral C, Armisen M. Nonpigmenting fixed drug eruption due to pseudoephedrine. Ann Allergy Asthma Inmunol. 1998;80(4):309-10.

17. Lopez Abad R, Iriarte Sotes P, Castro Murga M, Gracia Bara MT, Sesma Sanchez P. Fixed drug eruption induced by phenylepherine: a case of polysensitivity. J Investig Allergol Clin Immunol. 2009;19(4):322-3.

18. Bobadilla-Gonzalez P, Perez-Rangel I, GarciaMenaya JM, Sanchez-Vega S, Cordobes-Duran C, Zambonino-Carreiras MA. Type IV reaction due to phenylepherine administered nasally with crossreactivity with ethylepherine. J Investig Allergol Clin Immunol. 2011;21(1):69-72.

Cite this article as: Gupta MC, Rani M, Aggarwal K. Phenylepherine induced fixed drug eruption: a rare case of cross sensitivity. Int $\mathbf{J}$ Basic Clin Pharmacol 2016;5:1687-90. 